\section{Research thrives on integration of natural and social sciences}

Emerging collaborations between social and natural scientists face challenges, as you acknowledge (Nature 462, 825-826, 2009).

But, like A. D. Manning and J. Fischer in Correspondence (Nature 463, 425; 2010), you sidestep a practical question that keeps many laboratory doors closed: what if interactions with 'soft' scientists harm the quality of my 'hard' research?

The Center for Nanotechnology in Society at Arizona State University (ASU) has collaborated with natural scientists since 2005 . It also hosts the Socio-Technical Integration Research project (http://cns.asu.edu/stir), which embeds social scientists in 20 labs across ten nations on three continents - represented by three authors of this letter, plus the project's coordinator. Social researchers learn the theory and observe the methods of their laboratory counterparts, but they also introduce a protocol that unpacks social and ethical dimensions of the lab science itself in a real-time, hands-on, collaborative manner. The social scientists, their methods and enquiries become embedded in the laboratory during each 12-week engagement study.

We find that such integrative activities can trigger changes in laboratory practices - expanding the values and questions considered, and the alternatives that are perceived as viable. For example, reflections on responsible innovation generated novel ideas for antenna structures and nanoparticle synthesis for researchers at ASU's Center for Single Molecule Biophysics. Such developments often advance research and sometimes advance deliberation on public values. For laboratory scientists, thinking and talking about the broader dimensions of their work in an integrated way need not entail a sacrifice in productivity.
Rather, efforts to enhance scientific creativity and societal responsiveness can be mutually reinforcing.

Erik Fisher School of Politics and Global Studies, Arizona State University, PO Box 873902, Tempe, Arizona 85287-390, USA

e-mail: efisher1@asu.edu

Simon Biggs School of Process, Environmental and Materials Engineering, University of Leeds, UK Stuart Lindsay The Biodesign Institute, Arizona State University, USA Jie Zhao School of Materials Science and Engineering, Dalian University of Technology, China

\section{Rigid animal-rights views not useful to ethics debate}

Fern Wickson calls for animalrights activists to be formally consulted on university animalresearch programmes (Nature 463, 293; 2010). The UK practice of including lay members of the public on university animal-ethics committees might be a sounder strategy.

It is true that more productive dialogue ought to exist between scientists and protesters. But for the most vocal and militant activists, no compromise is acceptable. Their adherence to the cause is almost religious. Such rigid views are unlikely to add usefully to the discussion.

Rob Campbell Cold Spring Harbor Laboratory, Beckman Building, 1 Bungtown Road, Cold Spring Harbor, New York 11724, USA e-mail: campbell@cshl.edu

\section{New NMR machines are set to boost biomedical potential}

You made some excessively pessimistic assessments in your News Feature about the arrival of the first 1-gigahertz highresolution nuclear magnetic resonance (NMR) spectrometer at the European Centre for High
Field NMR, and its reception by the biological NMR community (Nature 463, 605-606; 2010).

To predict potential benefits from this advance, we should remember NMR's earlier contributions to biology and medicine, and not just focus on it as a structural tool.

By revealing the extent and timescale of conformational fluctuations in proteins, NMR enabled conformational selection to supplant induced fit as a paradigm for biomolecular recognition. Powerful approaches to drug discovery have been launched by protein NMR's ability to pinpoint site-specific interactions very rapidly.

Far from evidence of donor fatigue, there are signs in the United States that federal support for ultra-high-field NMR is growing. As recently as 2007 , only about a quarter of such instruments were purchased primarily with federal support. A rise in the cost limit for requests for high-end instrumentation from the US National Science Foundation and National Institutes of Health major-instrumentation programmes extends the reach of such requests to beyond 800-megahertz NMR machines.

Higher magnetic fields will soon be revealing biomedical insights we can scarcely imagine today. Jeffrey C. Hoch Gregory P. Mullen NMR Structural Biology Facility, University of Connecticut Health Center, Farmington, Connecticut 06030, USA e-mail: hoch@uchc.edu

\section{Skewed assessment values have stifled textbook-writing}

I welcome your Editorial encouraging career recognition for writers of science books (Nature 463, 588; 2010). But nothing will change for British scientists unless books are properly valued within the new Research Excellence Framework, which assesses the quality of research in UK

higher-education institutions.

Under the previous system, the Research Assessment Exercise, a 400-page peer-reviewed science textbook was allocated the same value as a single journal article. It made no difference if the book was cited hundreds of times and well-reviewed in academic journals. I must declare an interest: I wrote such a book (Pheromones and Animal Behaviour Cambridge Univ. Press, 2003).

Concerns about the chilling effects on textbook-writing by British academics have been highlighted before, to no avail (see, for example, go.nature.com/ nmq3Vq).

The scientists finalizing the new rules have the power to change the criteria and give textbook-writing more recognition. I hope they will. Tristram D. Wyatt Department of Zoology, University of Oxford, South Parks Road, Oxford OX13PS, UK e-mail: tristram.wyatt@zoo.ox.ac.uk

\section{Futures perfect - food for thought and welcome light relief}

Please do not listen to the likes of Denis Alexander (Nature 463, 425; 2010). Futures provides welcome light relief from the serious stuff preceding it, sometimes offering food for thought and - in the case quoted - such high comedy as to provoke what is colloquially known as a belly laugh, which I never dreamed I would experience in the company of your illustrious journal.

Robin Thompson Little Bookham Common, Surrey KT23 3HY, UK e-mail: bookham@msn.com

Contributions may be submitted to correspondence@nature. com. Please see go.nature.com/ cMCHno. Published contributions are edited. Comments and debate are also welcomed at our blog Nautilus (http://blogs.nature. com/nautilus). 